\title{
Development of new additive for grain refinement of austenitic stainless steel
}

\author{
M. Mizumoto*, S. Sasaki, T. Ohgai and A. Kagawa
}

Recently, a new additive for grain refinement of Ni based superalloys ${ }^{1,2}$ has been developed. In those studies, it was considered that niobium carbide in $\mathrm{Ni}-\mathrm{Nb}-\mathrm{C}$ alloy additives would act as nuclei on the solidification of $\mathrm{Ni}$ based superalloys. It is known that the crystallographic characteristics of iron are quite similar to those of nickel. Thus, it was expected that niobium carbide would act as a grain refiner for iron base alloys, especially for austenitic steels. In this study, the effect of the additives on the microstructure of SUS316 steel was examined in various experimental conditions. The grain size of SUS316 specimens without inoculation was $\sim 2700 \mu \mathrm{m}$. On the other hand, when $\mathrm{NbC}$ containing alloy additives were added into the SUS316 melt, fine equiaxed grains were observed and the grain size of the specimen was significantly reduced to $\sim 200 \mu \mathrm{m}$.

Keywords: Grain refinement, Inoculation, Austenitic stainless steel, SUS316, Niobium carbide?>

\section{Introduction}

In recent years, it is strongly required to reduce the weight of transport machines, mainly automobiles, to save the natural resources such as metallic elements and fossil fuel. To reduce the weight of those machines, it is essential to improve the strength of the metallic components built in. It is well known that mechanical properties of metallic materials, such as hardness, tensile strength and low cycle fatigue property, will be improved by decreasing the grain size of metallic materials. ${ }^{1-5}$ Thus it is expected that the weight of metallic components would be reduced efficiently by developing the grain refinement technique. Nowadays, several grain refinement techniques have been developed, such as rapid cooling process and low temperature casting process. However, those processes have some problems that the special equipments are required and that the size and the shape of the castings are limited due to their severe fabrication conditions. On the other hand, the inoculation method is the most promising method to solve those problems due to its very simple process. The authors have developed a new additive for grain refinement of $\mathrm{Ni}$ based superalloys ${ }^{1,2}$ and it was suggested that niobium carbide in the additives would act as nuclei on the solidification of $\mathrm{Ni}$ based superalloys. Since the crystallographic characteristics of nickel and iron are quite similar, it was expected that niobium carbide would be effective as well for the grain refinement of iron based alloys, especially for austenitic steels. In

Department of Materials Science and Engineering, Nagasaki University, 114 Bunkyo-machi, Nagasaki 852-8131, Japan

*Corresponding author, email mizumoto@ nagasaki-u.ac.jp this study, the effect of a new additive containing $\mathrm{NbC}$ on the microstructures of SUS316 austenitic stainless steel was examined.

\section{Experimental}

The chemical composition of SUS316 steel used in this study is shown in Table 1. Four types of additives were prepared as follows: first, $\mathrm{Fe}-\mathrm{C}$ alloys were prepared by melting electrolytic iron and electrode graphite in a high frequency induction furnace under an argon gas atmosphere. Then the $\mathrm{Fe}-\mathrm{C}$ alloys and pure niobium $(99 \cdot 5 \%$ purity) were alloyed by arc melting to obtain $\mathrm{Fe}-\mathrm{Nb}-\mathrm{C}$ alloys as additives. Microstructures of the $\mathrm{Fe}-\mathrm{Nb}-\mathrm{C}$ alloys were observed by an optical microscope and a scanning electron microscope (SEM). Inoculation treatment was carried out as follows: SUS316 steel of about $90 \mathrm{~g}$ was melted at $1773 \mathrm{~K}$ in an alumina crucible with inner diameter of $20 \mathrm{~mm}$. After holding at $1773 \mathrm{~K}$ for $30 \mathrm{~min}$, the alloy melt was cooled to $1726 \mathrm{~K}$ and held for $20 \mathrm{~min}$. Then, a certain amount of additive was added into the alloy melt. The alloy melt was stirred for $5 \mathrm{~s}$ with a silica tube and held for a predetermined time, followed by air cooling. The microstructure of the specimen was observed on the transverse sections with an optical microscope and the grain size was measured. The evaluation method of grain size is shown in Fig. 1. When grain size was macroscopic scale, it was measured on three concentric circles with $1 / 4 r, 1 / 2 r$ and $3 / 4 r$ in radius ( $r$ is the radius of the specimen) as shown in Fig. 1a. When grain size was small, of the order of micrometre, it was evaluated by counting the number of intersections of grain boundaries with the several lines randomly drawn on the microstructures of transverse section (Fig. 1b). 


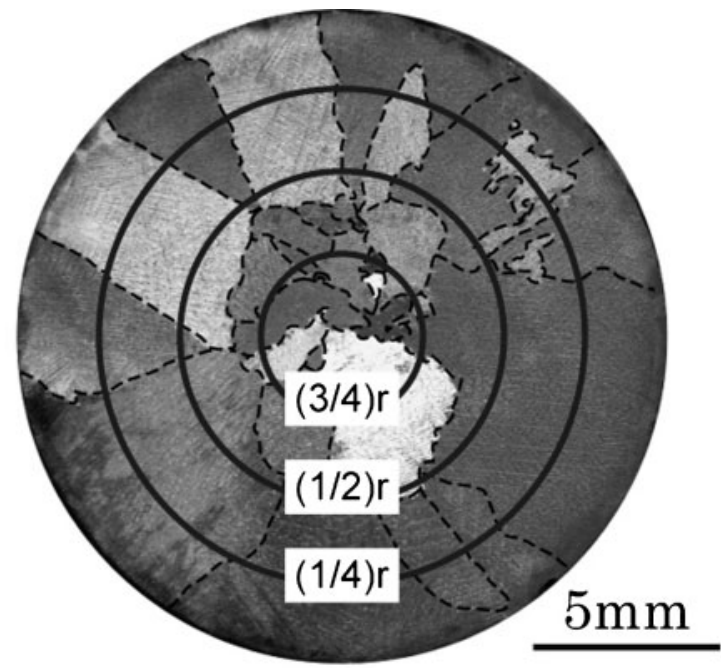

The average grain size : $\mathrm{G}=\mathrm{L} / \mathrm{n}$ ( $\mathrm{mm} /$ number) $※ \mathrm{~L}$ : The circumference of a circle measured.

$\mathrm{n}$ : The number of grains which (a) were intersected by the circle.

1 Evaluation method of grain size

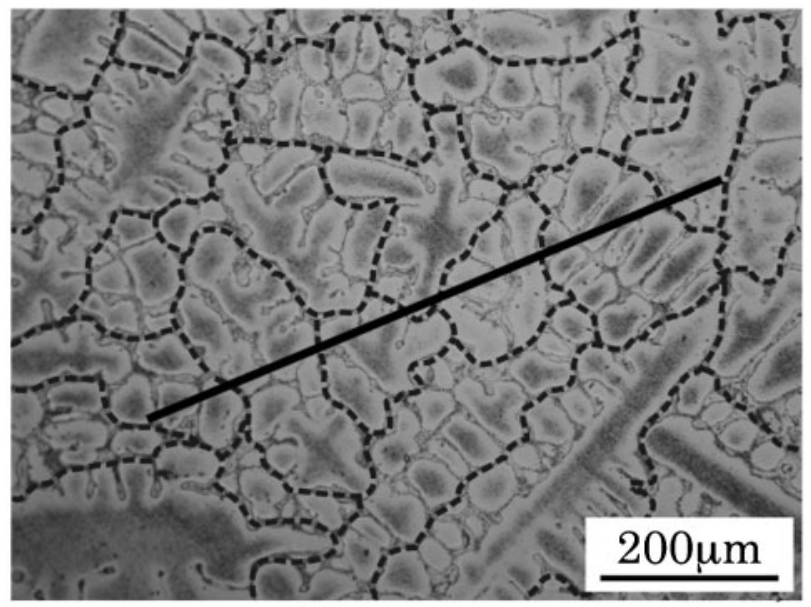

Microstructure

The average grain size : $\mathrm{G}=\mathrm{L} / \mathrm{n}$ ( $\mu \mathrm{m} /$ number) ※ : The circumference of the line.

$\mathrm{n}$ : The number of grains which were cut across by the line.

\section{Results and discussion}

\section{Microstructure of Fe-Nb-C alloy additives}

For comparison, the $\mathrm{Ni}-\mathrm{Nb}-\mathrm{C}$ alloy additive, which showed a significant effect on the grain refinement of nickel based superalloys, ${ }^{1,2}$ was added into molten SUS316 steel. The fine equiaxed grains were observed at the bottom part of the specimen and the rest was coarse columnar structure. This result indicates that the additive was not dispersed throughout the melt and sedimented at the bottom part of the crucible. In addition, the fine equiaxed grains observed at the bottom of the specimen suggest that a component in the $\mathrm{Ni}-\mathrm{Nb}-\mathrm{C}$ additive, possibly $\mathrm{NbC}$, has the effect on grain refinement of SUS316 steel. The calculated specific weight of $\mathrm{Ni}-\mathrm{Nb}-\mathrm{C}$ alloy additive and molten SUS316 steel are 7980 and $7250 \mathrm{~kg} \mathrm{~m}^{-3}$ at $1450 \mathrm{~K}$ respectively. The specific weight of the $\mathrm{Ni}-\mathrm{Nb}-\mathrm{C}$ alloy additive is much larger than that of SUS316 steel. This difference of the specific weight is considered to be attributable to the sedimentaion of the additive at the bottom part of the specimen. To avoid the sedimentaion of the additive, $\mathrm{Fe}-\mathrm{Nb}-\mathrm{C}$ alloys which involve $\mathrm{NbC}$ crystals and have almost the same specific weight

Table 1 Chemical composition of SUS 316 steel, mass\%

\begin{tabular}{lllllllll}
\hline C & Si & Mn & P & S & Ni & Cr & Mo & Fe \\
\hline 0.08 & 1.00 & 2.00 & 0.045 & 0.030 & 18 & 12 & 2.5 & Bal. \\
\hline
\end{tabular}

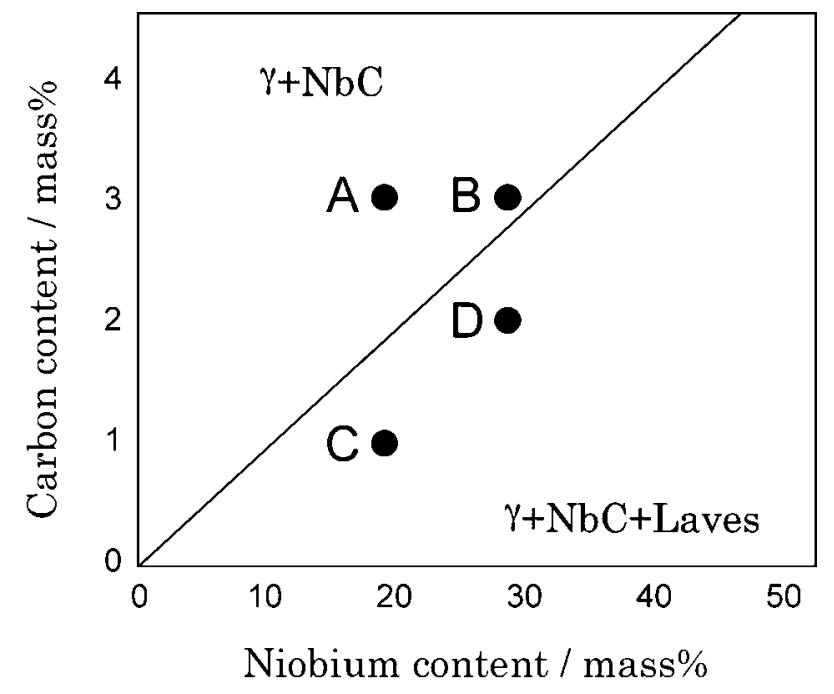

2 Phase constituents of $\mathrm{Fe}-\mathrm{Nb}-\mathrm{C}$ ternary system

as that of molten SUS316 steel were prepared as additives. Figure 2 shows the phase constituent diagram of ternary $\mathrm{Fe}-\mathrm{Nb}-\mathrm{C}$ system $^{6}$ and the chemical composition of four $\mathrm{Fe}-\mathrm{Nb}-\mathrm{C}$ alloys used in this study. Figure 3 shows the microstructures of the four types of $\mathrm{Fe}-\mathrm{Nb}-\mathrm{C}$ alloy additives. Coarse primary $\mathrm{NbC}$ crystals were observed in the microstructure of all specimens. The area fractions of primary $\mathrm{NbC}$ 

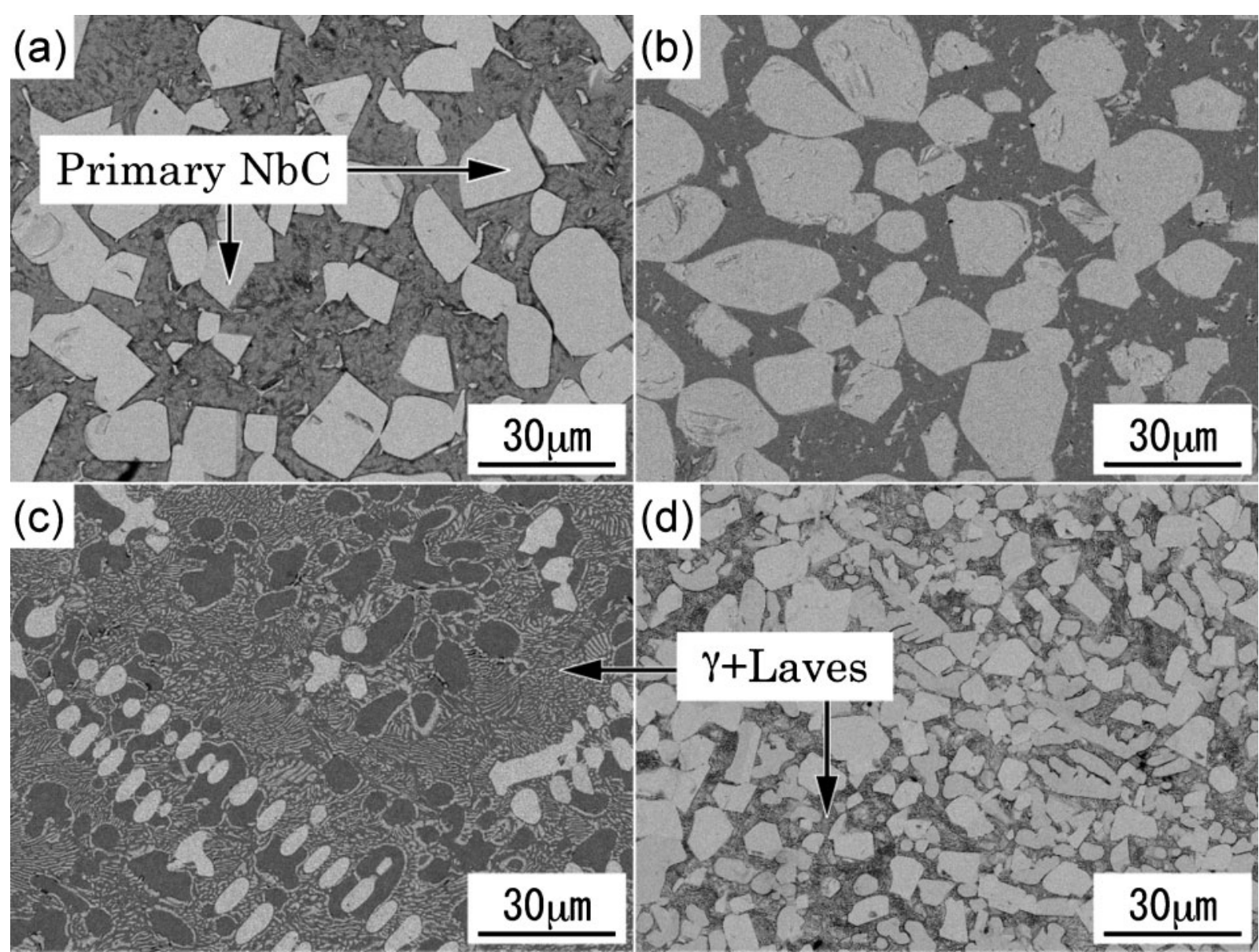

a Fe-20Nb-3.0C alloy (additive A); $b$ Fe-30Nb-3.0C alloy (additive B); $c$ Fe-20Nb-1.0C alloy (additive C); $d$ Fe-30Nb-2.0C alloy (additive D)

3 Microstructures of $\mathrm{Fe}-\mathrm{Nb}-\mathrm{C}$ alloys

crystals in the additives $\mathrm{A}, \mathrm{B}, \mathrm{C}$ and $\mathrm{D}$ measured by image analysis were $36 \cdot 9,38 \cdot 2,8 \cdot 3$ and $36 \cdot 3 \%$ respectively. The matrix structure in the additives $\mathrm{C}$ and $\mathrm{D}$ are a eutectic consisting of $\gamma$ and $\mathrm{Fe}_{2} \mathrm{Nb}$ (Laves phase).

\section{Effect of amount of additives on grain size}

To investigate the effect of amount of additive on the grain size of SUS316 steel, the additive D (1.0-3.0 mass $\%)$ were added into molten SUS316 steel. The granule size of the additive was sieved to $0 \cdot 5-1 \mathrm{~mm}$. The holding time was $0 \mathrm{~s}$. Figure 4 shows the macrostructures of SUS316 steel after addition of various amounts of the additive $\mathrm{D}$. The relationship between the grain size and the amount of additive is shown in Fig. 5. When the amount of additive was 0-2 mass $\%$, coarse columnar structure was observed as shown in Fig. $4 a-c$. On the other hand, when the amount of additive was 3 mass $\%$, fine equiaxed grains were observed over the whole area of the section (Fig. 4d) and grain size was significantly reduced to $210 \mu \mathrm{m}$. These results indicate that the amount of additive more than $3 \mathrm{mass} \%$ is required to achieve the grain refinement of SUS316 steel.

\section{Effect of holding time on grain size}

To investigate the effect of holding time on the grain size, molten SUS316 steel was held for various periods after the addition of additive D of 3 mass $\%$ at $1726 \mathrm{~K}$. Macrostructures and average grain sizes of the specimens for different holding time are shown in Figs. 6 and 7 respectively. When the holding time was $0 \mathrm{~s}$ without stirring, fine equiaxed grains were observed at the centre of the specimen as shown in Fig. $6 a$. When the holding time was $0 \mathrm{~s}$ after stirring for $5 \mathrm{~s}$, fine equiaxed grains were observed (Fig. 6b) and the grain size was $\sim 210 \mu \mathrm{m}$. However, when the holding time was 5-10 s, coarse columnar structures were observed (Fig. $6 c$ and $d$ ) and the effect of additives seems to disappear. It is suggested that the $\mathrm{Fe}-\mathrm{Nb}-\mathrm{C}$ alloy additives with granule size of $0.5-1 \mathrm{~mm}$ would have very high dissolution rate in the melt of SUS316 steel.

Figure 8 shows the experimental result of the addition of additive $D$ with a larger granule size $1 \sim 1.5 \mathrm{~mm}$ for different holding times. In this case, refining effect of the additive was maintained up to $45 \mathrm{~s}$ (Fig. 7) and this suggests that the grain refinement of SUS316 steel in this study resulted from the addition of $\mathrm{Fe}-\mathrm{Nb}-\mathrm{C}$ alloy additives and not from the rapid cooling of the melt caused by the inoculation. Therefore, the optimum conditions for the grain refinement of SUS316 are as follows: the inoculation temperature $1726 \mathrm{~K}$, the stirring time $5 \mathrm{~s}$, the holding time $0 \mathrm{~s}$ for the granule size of the 


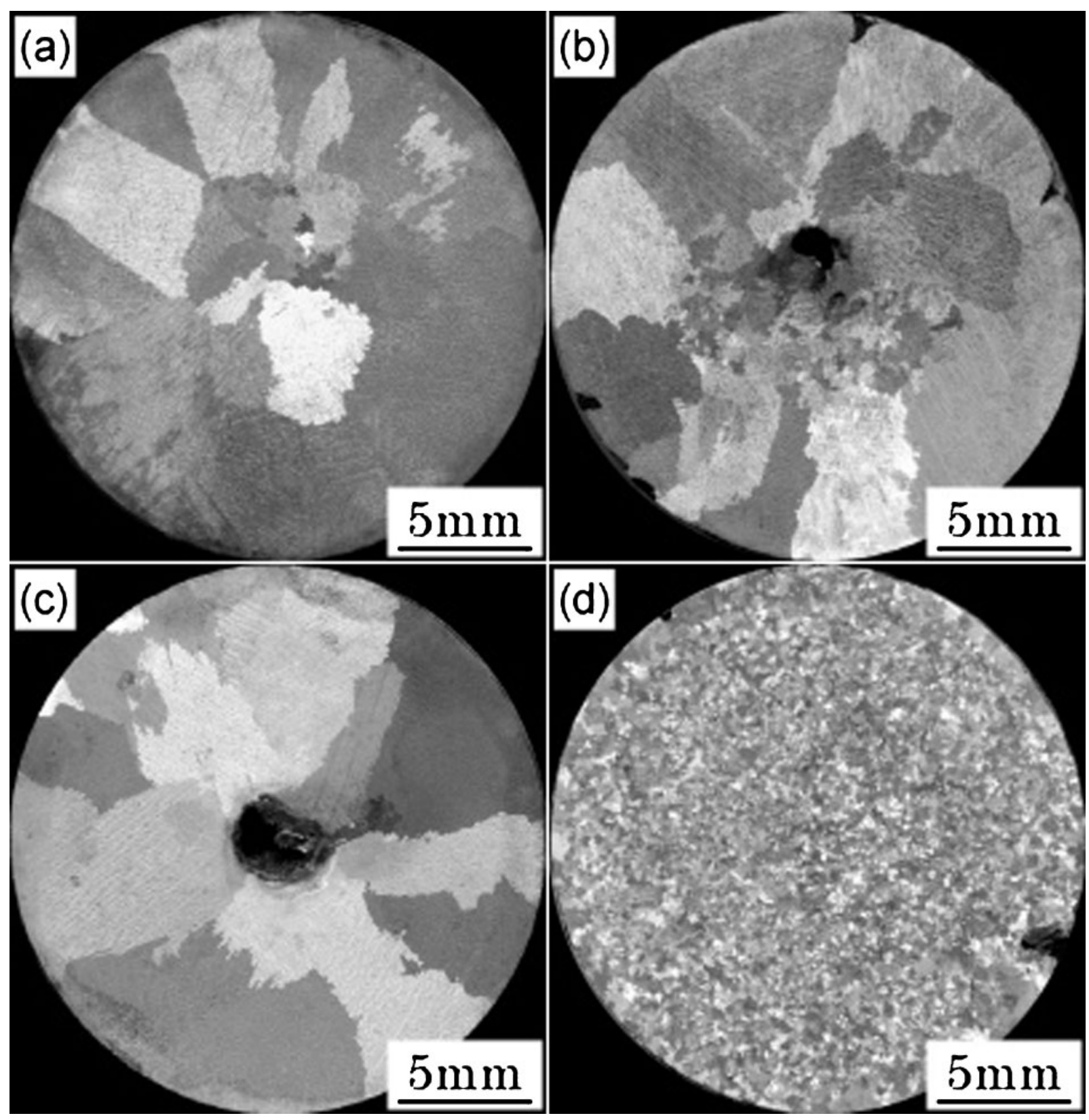

a no addition; $b 1$ mass\%; c 2 mass\%; $d 3$ mass $\%$

4 Macrostructure of SUS316 steel after addition of various amounts of additives D

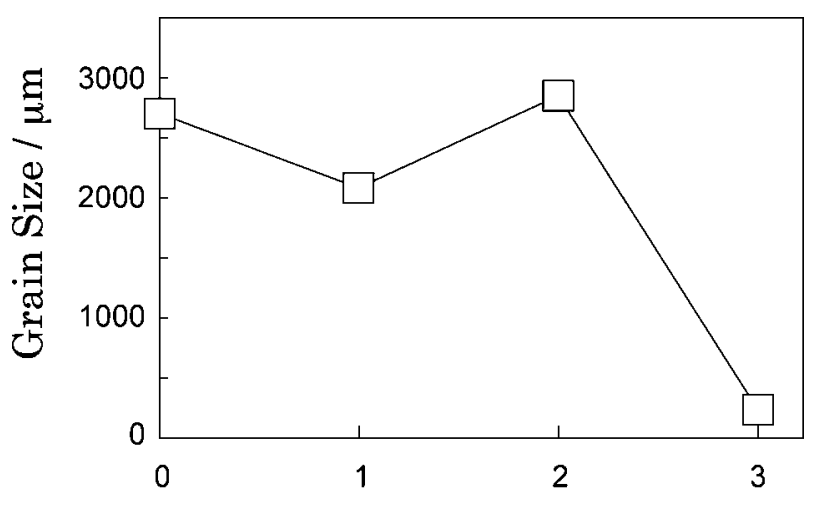

Amount of additives / mass \%

5 Effect of amount of additive D on grain size additive $0 \cdot 5-1 \mathrm{~mm}$ and $0-20 \mathrm{~s}$ for the granule size of $1-1 \cdot 5 \mathrm{~mm}$.

\section{Effect of area fraction of primary $\mathrm{NbC}$ crystals on grain size}

In the previous works on the grain refinement of $\mathrm{Ni}$ based superalloys, it was found that more than $10 \%$ of the area fraction of primary $\mathrm{NbC}$ crystal in the $\mathrm{Ni}-$ $\mathrm{Nb}-\mathrm{C}$ alloy additives was required to achieve the grain refinement. Thus, it was expected in this study, that the area fraction of primary $\mathrm{NbC}$ in the $\mathrm{Fe}-\mathrm{Nb}-$ $\mathrm{C}$ alloy additives would influence the grain refinement. In the experiments, four additives which have various area fractions of primary $\mathrm{NbC}$ shown in 


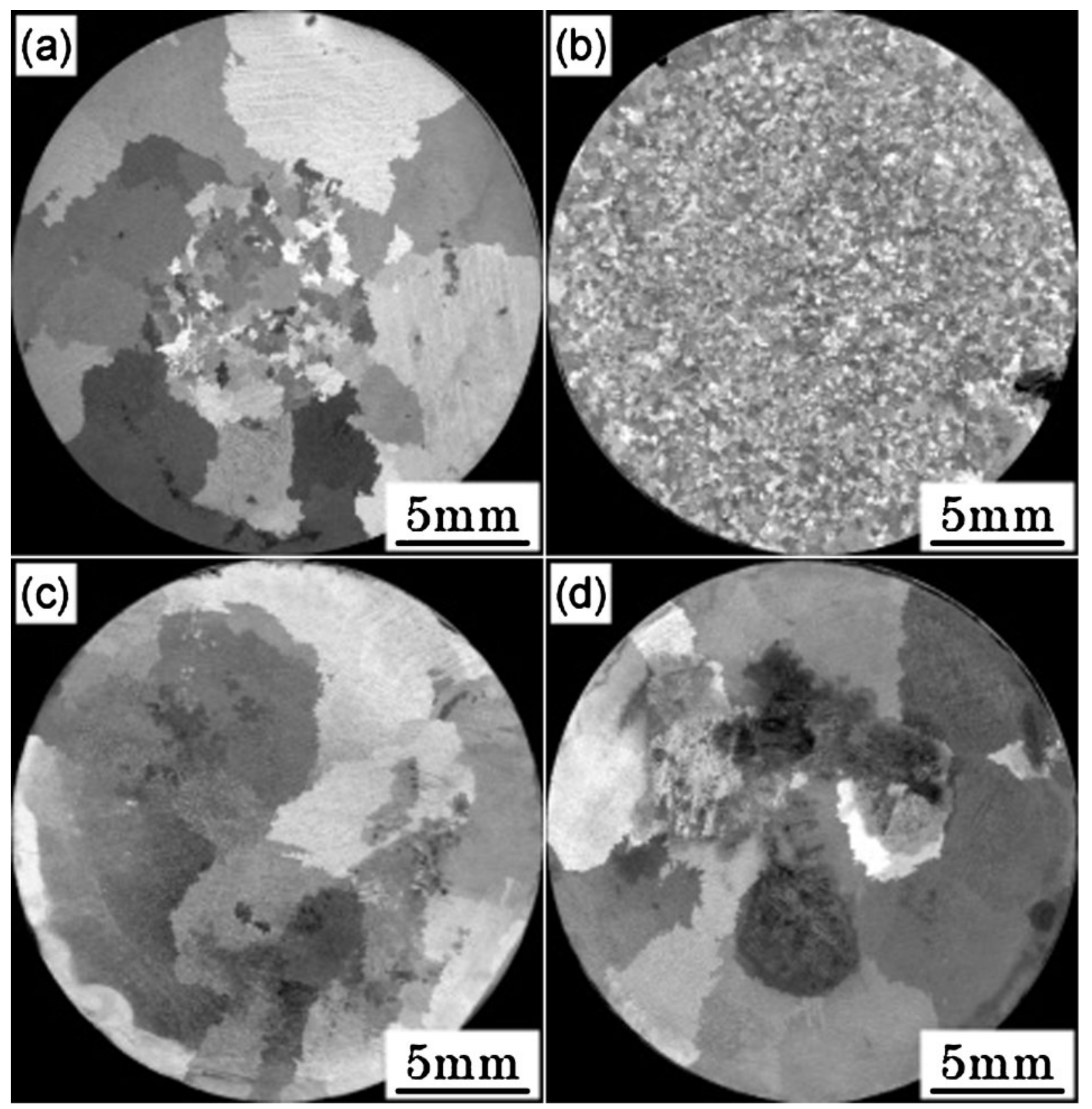

$a$ no stirring and holding for $0 \mathrm{~s} ; b$ stirring for $5 \mathrm{~s}$ and held for $0 \mathrm{~s} ; c$ stirring for $5 \mathrm{~s}$ and held for $5 \mathrm{~s} ; d$ stirring for $5 \mathrm{~s}$ and held for $10 \mathrm{~s}$

6 Effect of holding time on macrostructure of SUS316 steel (additive D with $0.5-1 \mathrm{~mm}$ in granule size)

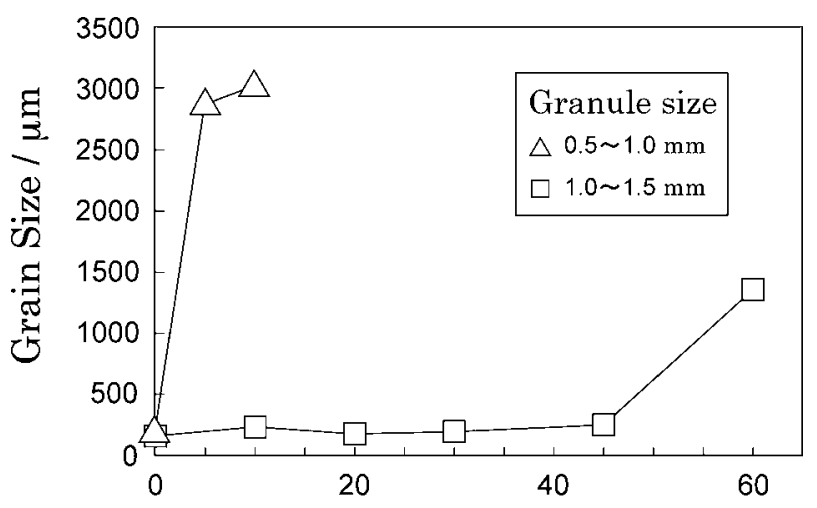

Holding time / sec

7 Relationship between grain size and holding time for different granule size of additive D
Fig. 2 were added into the molten SUS316 steel. The experimental condition was the optimum conditions for the grain refinement as mentioned before. The macrostructures of four specimens with the addition of additive A-D are shown in Fig. 9. In the cases of the additive $\mathrm{A}, \mathrm{B}$ and $\mathrm{D}$, fine equiaxed grains with the grain size of $\sim 200 \mu \mathrm{m}$, were observed, while slight coarse equiaxed grains, $\sim 1000 \mu \mathrm{m}$, were observed in the case of additive $\mathrm{C}$, as shown in Fig. $8 c$. Figure 10 shows the relationship between the area fraction of primary $\mathrm{NbC}$ and the grain size. When the area fraction of primary $\mathrm{NbC}$ was lower than $10 \%$, the effect of the additive on the grain refinement was not so significant. 


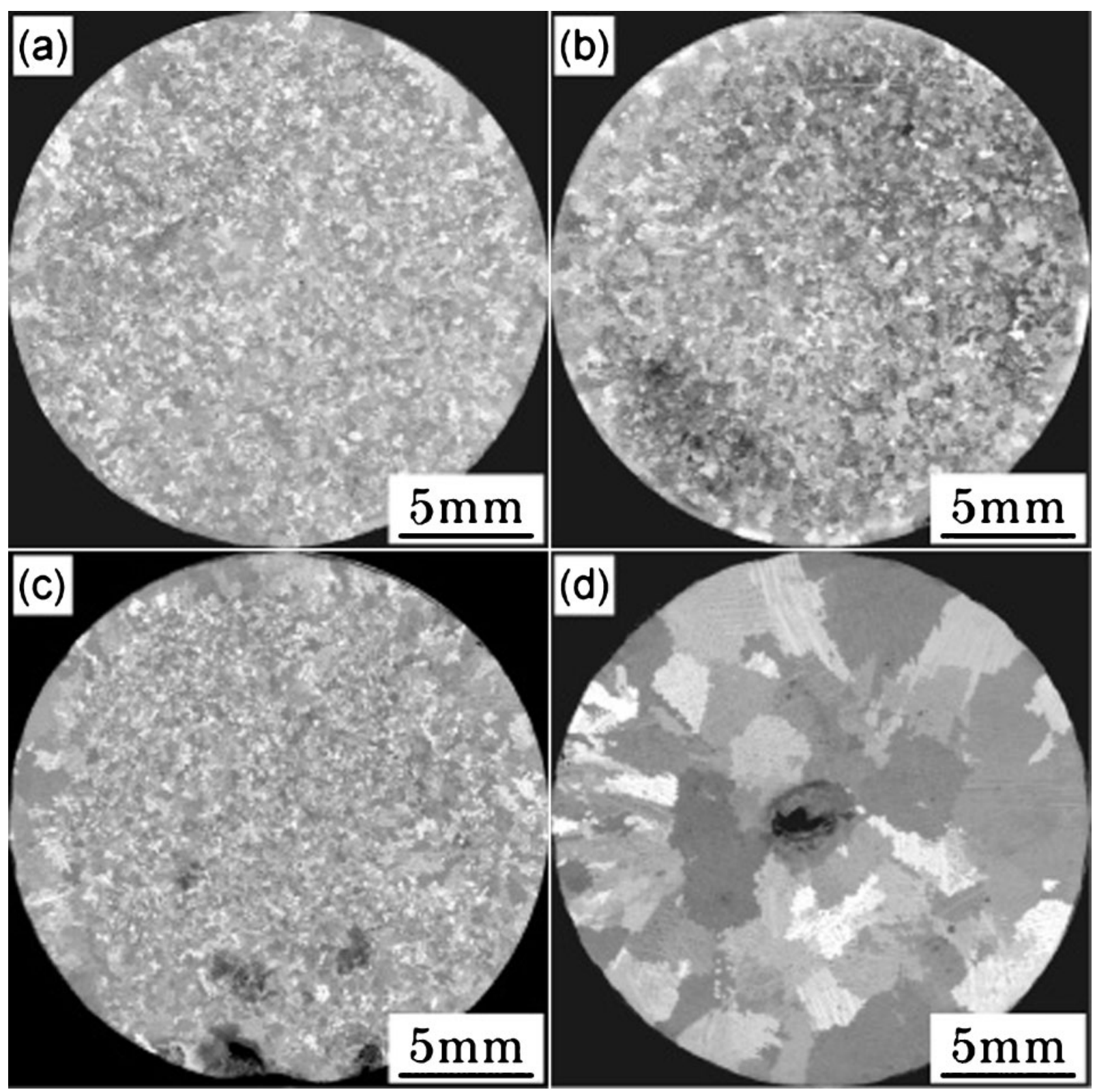

a stirring for $5 \mathrm{~s}$ and held for $0 \mathrm{~s} ; b$ stirring for $5 \mathrm{~s}$ and held for $10 \mathrm{~s} ; c$ stirring for $5 \mathrm{~s}$ and held for $20 \mathrm{~s}$; $d$ stirring for $5 \mathrm{~s}$ and held for $60 \mathrm{~s}$

8 Effect of holding time on macrostructure of SUS316 steel (additive D with 1-1.5 mm in granule size)

\section{Conclusions}

1. The area fraction of primary $\mathrm{NbC}$ crystals in $\mathrm{Fe}-$ $\mathrm{Nb}-\mathrm{C}$ alloy additives tends to increase with increasing $\mathrm{Nb}$ and $\mathrm{C}$ concentrations of the additives.

2. When the amount of additives was less than 3 mass $\%$, coarse columnar structure was observed. On the other hand, when the amount of additive was 3 mass $\%$, fine equiaxed grains were observed and grain size was significantly reduced to $210 \mu \mathrm{m}$. This indicates that the primary $\mathrm{NbC}$ crystals would act as nuclei for primary $\gamma$ on solidification of SUS316 steel.

3. When the holding time after the addition of additives and the subsequent stirring of the melt was over $5 \mathrm{~s}$, no effect was observed for a finer additive with granule size of $0.5-1 \mathrm{~mm}$, indicating that the additive dissolved rapidly into the melt. On the other hand, when a coarser additive with granule size of $1-1.5 \mathrm{~mm}$ was employed, the refiner effect was maintained up to $45 \mathrm{~s}$.

4. Optimum conditions for the grain refinement of SUS316 are as follows: the inoculation temperature $1726 \mathrm{~K}$, the stirring time $5 \mathrm{~s}$, the holding time $0 \mathrm{~s}$ for the additive the granule size of $0 \cdot 5-1 \mathrm{~mm}$ and $0-20 \mathrm{~s}$ for the additive with granule size of $1-1.5 \mathrm{~mm}$.

5. When the area fraction of primary $\mathrm{NbC}$ crystals in the additives was lower than $10 \%$, the effect of the $\mathrm{Fe}-$ $\mathrm{Nb}-\mathrm{C}$ alloy additives was not significant and thus additives having a higher area fraction of $\mathrm{NbC}$ are desirable to achieve the grain refinement of SUS316 steel. 


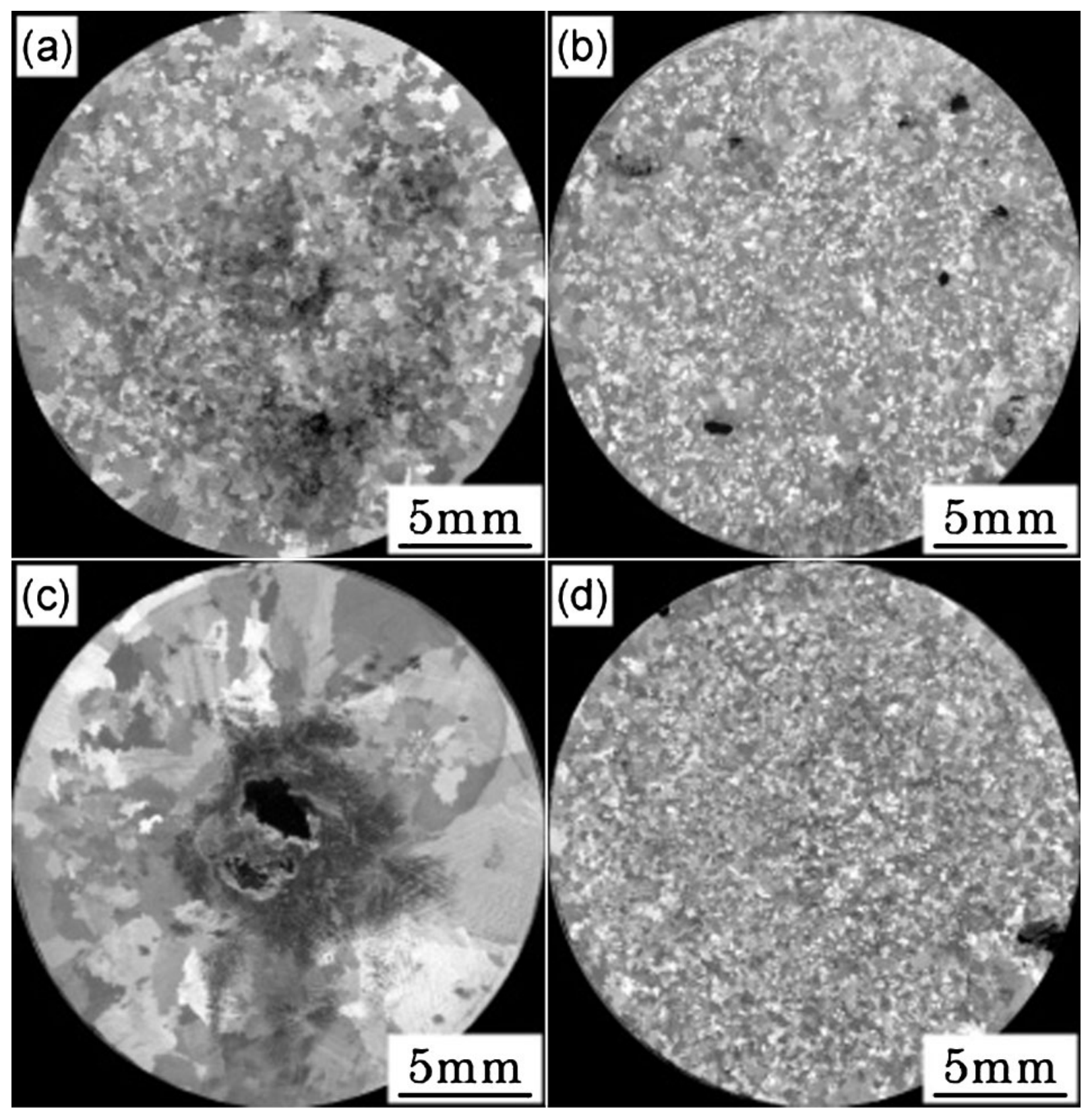

$a$ additive $A ; b$ additive $B ; c$ additive $C ; d$ additive D

9 Macrostructures of SUS316 steels after inoculation with additives having different area fractions of $\mathrm{NbC}$

\section{References}

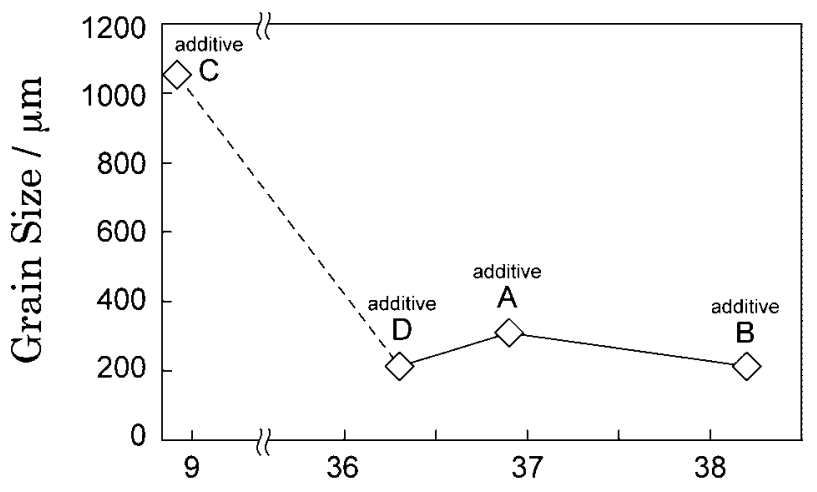

1. M. Mizumoto, S. Nomura and A. Kagawa: Trans. Ind. Inst. Met., $2005, \mathbf{5 8}, 597-602$

2. M. Mizumoto, T. Ohgai and A. Kagawa: Proc. 148th JFS Meet., Osaka, Japan, May 2006, Osaka Sangyo University, Paper 25.

3. L. Liua, T. Huanga, Y. Xiongb, A. Yangc, Z. Zhaoa, R. Zhanga and J. Lia: Mater. Sci. Eng., 2005, 394, 1-8.

4. W. Jin, F. Bai, T. Li and G. Yin: Mater. Lett., 2007, 62, 1585-1588.

5. C. N. Wei, H. Y. Bor, C. Y. Ma and T. S. Lee: Mater. Chem. Phys., 2003, 80, 89-93.

6. H. Ohtani, M. Hasebe and T. Nishizawa: CALPHAD, 1989, 13, 183-204.

Area fraction of $\mathrm{NbC} / \%$

10 Effect of area fraction of $\mathrm{NbC}$ in additives on grain size of SUS316 steel 